\title{
Effect of spermidine on ameliorating spermatogenic disorders in diabetic mice via regulating glycolysis pathway
}

\author{
Jin-Yuan Wang ${ }^{1 \dagger}$, Duo Ma ${ }^{1 \dagger}$, Min Luo ${ }^{1 \dagger}$, Yong-Peng Tan'1, Ou Zhong ${ }^{1}$, Ge Tian', Yong-Ting Lv' ${ }^{1}$, Mei-Xiang Li', \\ Xi Chen ${ }^{1}$, Zhi-Han Tang ${ }^{2^{*}}$, Lin-Lin Hu ${ }^{3^{*}}$ and Xiao-Can Lei ${ }^{1,2^{*}}$
}

\begin{abstract}
Diabetes mellitus (DM), a high incidence metabolic disease, is related to the impairment of male spermatogenic function. Spermidine (SPM), one of the biogenic amines, was identified from human seminal plasma and believed to have multiple pharmacological functions. However, there exists little evidence that reported SPM's effects on moderating diabetic male spermatogenic function. Thus, the objective of this study was to investigate the SPM's protective effects on testicular spermatogenic function in streptozotocin (STZ)-induced type 1 diabetic mice. Therefore, 40 mature male C57BL/6 J mice were divided into four main groups: the control group $(n=10)$, the diabetic group $(n=10)$, the $2.5 \mathrm{mg} / \mathrm{kg}$ SPM-treated diabetic group $(n=10)$ and the $5 \mathrm{mg} / \mathrm{kg}$ SPM-treated diabetic group $(n=10)$, which was given intraperitoneally for 8 weeks. The type 1 diabetic mice model was established by a single intraperitoneal injection of STZ $120 \mathrm{mg} / \mathrm{kg}$. The results showed that, compare to the control group, the body and testis weight, as well the number of sperm were decreased, while the rate of sperm malformation was significantly increased in STZ-induced diabetic mice. Then the testicular morphology was observed, which showed that seminiferous tubule of testis were arranged in mess, the area and diameter of which was decreased, along with downregulated anti-apoptotic factor (Bcl-2) expression, and upregulated pro-apoptotic factor (Bax) expression in the testes. Furthermore, testicular genetic expression levels of Sertoli cells (SCs) markers (WT1, GATA4 and Vimentin) detected that the pathological changes aggravated observably, such as the severity of tubule degeneration increased. Compared to the saline-treated DM mice, SPM treatment markedly improved testicular function, with an increment in the body and testis weight as well as sperm count. Pro-apoptotic factor (Bax) was down-regulated expression with the up-regulated expression of Bcl-2 and suppression of apoptosis in the testes. What's more, expression of WT1, GATA4, Vimentin and the expressions of glycolytic rate-limiting enzyme genes (HK2, PKM2, LDHA) in diabetic testes were also upregulated by SPM supplement. The evidence derived from this study indicated that the SMP's positive effect on moderating spermatogenic disorder in T1DM mice's testis. This positive effect is delivered via promoting spermatogenic cell proliferation and participating in the glycolytic pathway's activation.
\end{abstract}

Keywords: Diabetes, Spermidine, Spermatogenic dysfunction, Glycolytic pathway, Sertoli cells

\footnotetext{
*Correspondence: 9906430@qq.com; hutwolin@126.com; 2019000013@usc. edu.cn

†Jin-Yuan Wang, Duo Ma and Min Luo are first authors.

${ }_{2}^{2}$ Postdoctoral Station for Basic Medicine, Hengyang Medical College, University of South China, Hengyang 421001, Hunan, China

${ }^{3}$ China Reproductive Medicine Center, The Affiliated Hospital of Youjiang Medical University for Nationalities, Baise 533000, Guangxi, China Full list of author information is available at the end of the article
}

\begin{abstract}
Introduction
Diabetes mellitus (DM) is a group of metabolic diseases characterized by chronic hyperglycemia due to a variety of genetic and environmental causes, which were now 366 million DM people around the world [1]. Moreover, in patients between the ages of 18 and
\end{abstract}

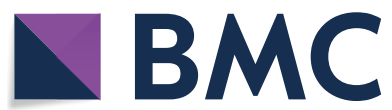

(c) The Author(s) 2022. Open Access This article is licensed under a Creative Commons Attribution 4.0 International License, which permits use, sharing, adaptation, distribution and reproduction in any medium or format, as long as you give appropriate credit to the original author(s) and the source, provide a link to the Creative Commons licence, and indicate if changes were made. The images or other third party material in this article are included in the article's Creative Commons licence, unless indicated otherwise in a credit line to the material. If material is not included in the article's Creative Commons licence and your intended use is not permitted by statutory regulation or exceeds the permitted use, you will need to obtain permission directly from the copyright holder. To view a copy of this licence, visit http://creativecommons.org/licenses/by/4.0/. The Creative Commons Public Domain Dedication waiver (http://creativeco mmons.org/publicdomain/zero/1.0/) applies to the data made available in this article, unless otherwise stated in a credit line to the data. 
30 , the prevalence was $6.5 \%$ higher in males than in females, especially in the one who had more reproductive needs [2]. As well, diabetes occurs due to sedentary life style and usage of advanced glycation end-products (AGE) in diets [3], which leads to multiple organ damage as nephropathy, cardiovascular and so on $[4,5]$. It's worth noting that male reproductive disorder is becoming one of the common complications of DM recently, such as hyposexuality, impotency and decreased fertility [6]. In particular, it can cause testicular spermatogenic dysfunction, which include damaged testicular normal structural, impaired structural and functional of SCs, decreased sperm number and motility as well increased abnormal sperm numbers $[7,8]$. However, the molecular mechanisms underlying DM-induced male reproductive dysfunction is not clear.

Spermidine (SPM) has been found for the first time in semen, well-known as polyamines medicine that promotes health and anti-aging $[9,10]$. Studies have shown that SPM possess multiple pharmacological functions including anti-inflammatory, promote autophagy, antioxidant, protecting the health of the nervous system and cardiovascular system [9]. Recently, several evidences have instructed the protective effects of SPM on the male reproductive damage induced by electromagnetic field, chemotherapy drugs [11]. In a diabetic animal model, SPM could attenuate diabetic myocardial fibrosis via inhibition of the canonical Wnt signaling pathway-mediated abnormal autophagy in male mice [12]. Diabetic hemoglobin glycation and lipid peroxidation induced could be alleviated by the antioxidant stress function of SPM intervention [13]. Besides, SPM could exert effects on decreasing bodyweight by improving glucose utilization [14]. However, there are few reports on the effect of SPM on improving diabetic spermatogenic disorders in male. Detailed investigation into the molecular mechanisms underlying SPM-mediated protective effects on male reproductive dysfunction induced by DM is required.

In this study, we aimed to clarify whether SPM could improve the structural function of SCs, and the protective effects of SPM on spermatogenic dysfunction by regulating glycolytic pathways in streptozotocin (STZ)-induced diabetic mice. Sperm parameters, the testicular protein levels of apoptosis-related factors (Bax, Bcl-2), SCs marker (WT1, GATA4, Vimentin), key enzyme genes for glycolysis (HK2, PKM2, LDHA) were detected closely. The present study may further advance our understanding of molecular mechanisms of SPM-mediated protective effects on DM-induced male reproductive dysfunction.

\section{Materials and methods}

Animals and experimental groups

Healthy 6-week-old 20g male C57BL6J mice were purchased from the University of South China (Animal Permit NO: USC2020031602). All experimental procedures were approved by Laboratory Animal Welfare Ethics Committee (NO: 2021USA0628), University of South China. For the induction of type 1 diabetes (T1DM), mice were intraperitoneally injected single dose of $120 \mathrm{mg} / \mathrm{kg}$ STZ (Sigma S-0130) dissolved in $0.1 \mathrm{M}$ citrate buffer at $\mathrm{pH} 4.5$ [15]. We monitor the fasting blood glucose levels for 3 consecutive days after STZ injection, considering mice with fasting glucose levels $\geq 11.1 \mathrm{mM}$ as diabetic.

After the STZ injection, we divide mice into four main groups, treating daily for 8 weeks with the following protocol. As the control group (control group, $n=10$ ) and $\mathrm{DM}+$ saline group (model group, $n=10$ ), which received orally administered physiological saline $(1 \mathrm{~mL} / \mathrm{kg} / \mathrm{d})$. $\mathrm{DM}+2.5 \mathrm{mg} / \mathrm{kg}$ SPM (Sigma, S-2501) group $(n=10)$ [11] and $\mathrm{DM}+5 \mathrm{mg} / \mathrm{kg}$ SPM group $(n=10)$ [12]. The SPM was dissolved in physiological saline, which was administered by intraperitoneal injection to the mice. After the last treatment, animals were anesthetized by intraperitoneal administration of $0.6 \mathrm{mg} / \mathrm{kg}$ Urethane. We collect relevant tissues for further analysis.

\section{Assessment of sperm number, abnormal sperm rate}

The caudal epididymis was dissected and placed in $1.5 \mathrm{~mL}$ of saline media heated to $37^{\circ} \mathrm{C}$, and then cut up the tissue, to give motility sperm time to escape into liquid, the caudal epididymis was left undisturbed for $20 \mathrm{~min}$. Sperm morphology were observed by stained with eosin-Y [16]. At the same time, we count the abnormal sperm and calculate the abnormal sperm rate. However, the evaluation of the sperm motility was not carried out impetuously with regard to avoidance of time.

\section{Histopathologic and the area and diameter of seminiferous} tubules analyses

The left testis, epididymis were removed and fixed in $4 \%$ polyoxymethylene overnight for histological analysis. And the tissue was embedded in paraffin and cut $4 \mu \mathrm{m}$ thickness by microtome. The slides were stained with hematoxylin and eosin (H\&E) for observing the morphology. Then, the diameters and area of 50 seminiferous tubules from each group were randomly evaluated by using an ocular micrometer with a light microscope.

\section{Quantitative real-time polymerase chain reaction (qRT -PCR)}

Total RNA from mice testicular tissues was extracted using TRIzol reagent (Invitrogen, Carlsbad, USA). 
mRNA was reverse converted into cDNA using the PrimeScript 1st strand cDNA Synthesis Kit (Takara Bio, Dalian, China). Real-time PCR was performed on an ABI7900 PCR system (Applied Biosystems, Foster City, USA) using SYBR Green Real-Time PCR Master Mix (ThermoFisher SCIENTIFIC NO:4309155). Endogenous GAPDH control was used as an internal control for relevant mRNA expression [17]. The relative expression of PCNA mRNA was assessed using the comparative $\mathrm{Ct}$ method. The sequences of the primers used are shown in Table 1.

Table 1 Primers sequences used as target and reference genes used in qPCR reactions

\begin{tabular}{lll}
\hline Gene & $\begin{array}{l}\text { Sequence of forward and reverse } \\
\text { primers 5'-3' }\end{array}$ & Accession no. \\
\hline Bax & F:TGCAGAGGATGATTGCTGAC & NM_007527.3 \\
BCl-2 & F:GATCAGCTCGGGCACTTTAG & NM_177410.2 \\
& R:ATGCCGGTTCAGGTACTCAG & \\
LDHA & F:ACTGTGTAACTGCGAACTCC & BC094019.1 \\
& R:GGGAATATGAACTTGAAGA & \\
HK2 & F:CGTGGTAAATGACACAGTTG & BC054472.1 \\
& R:AGTTCCACATTACGCATCTC & \\
PKM2 & F:CAGTACAGAATACACACCCA & BC094663.1 \\
& R:GTCATGTCTTATGTGTGGGT & \\
GATA4 & F:ATGCCTGTGGCTCTATCAC & AF179424.1 \\
& R:GGTGGTGTAGTCTGGCAGT & \\
WT1 & F:ATCCGCAACCAAGGATACAG & DQ537939.1 \\
& R:GGTCCTCGTGTTTGAAGGAA & \\
\hline
\end{tabular}

\section{Western blot}

The testis lysed in ice-cold RIPA lysis buffer (Promega corporation, Madison Wi, $\mathrm{uSa}$ ) and centrifuged $\mathrm{t}$ $14,000 \mathrm{rpm}$ for $10 \mathrm{~min}$ at $4{ }^{\circ} \mathrm{C}$. The concentrations of total protein in the whole-cell lysate were calculated via Bradford's procedure. An equal amount $(20 \mu \mathrm{g})$ of protein in each sample was separated by $12 \%$ sodium dodecyl sulphate-polyacrylamide gel electrophoresis and then transferred to a polyvinylidenedifluoride (PVDF) membranes (Millipore, Billerica, MA, USA). The membranes were incubted via primitive antibodies overnight at $4{ }^{\circ} \mathrm{C}$ with horseradish peroxidase-conjugated goat anti-rabbit IgG $(\mathrm{H}+\mathrm{L})$ secondary antibody, Alexa Fluor 594 (R37117) and immersed in ECL Plus Western Blotting detection reagent and displayed on Hyperfilm ECL (both from Amersham, Piscataway, NJ, USA). The band's intensity was determined using Lab Works 4.5 software (UVP, Upland, CA, USA) [18]. The primary antibodies used for Western blotting were tubulin, HK2, PKM2, LDHA. The information of antibody used in the experiment are shown in Table 2.

Immunohistochemical analysis of apoptosis-related factors (Bax, Bcl-2), SCs marker (Vimentin) and key enzyme genes for glycolysis (HK2, PKM2, LDHA)

The 4- $\mu \mathrm{m}$-thick dewaxed slices were rehydrated using gradient ethanol, incubated with pH6.0 citrate buffer with an application of high voltage for $3 \mathrm{~min}$. Then, the sections were incubated with a monoclonal mouse antibody against Bax, Bcl-2, Vimentin, HK2, PKM2, LDHA primary antibodies followed by anti-rabbit $\mathrm{IgV}$ for $60 \mathrm{~min}$

Table 2 antibody used as target and reference used in immunohistochemistry and Western Blot reactions

\begin{tabular}{|c|c|c|c|c|}
\hline Antibody & Company & Accession no. & $\begin{array}{l}\text { Concentration } \\
\text { of antibodies in } \\
\text { immunohistochemistry }\end{array}$ & $\begin{array}{l}\text { Concentration of } \\
\text { antibodies in Western } \\
\text { Blot }\end{array}$ \\
\hline Vimentin (D21H3) XP ${ }^{\circledR}$ Rabbit mAb & Cell Signaling Technology & \#5741 & $1: 200$ & \\
\hline LDHA (C4B5) Rabbit mAb & Cell Signaling Technology & \#3582 & $1: 200$ & $1: 1000$ \\
\hline PKM2 (D78A4) XP ${ }^{\circledR}$ Rabbit mAb & Cell Signaling Technology & \#4053 & $1: 500$ & $1: 1000$ \\
\hline HK2 Rabbit pAb (A0994) & ABclonal Technology & \#3099 & $1: 200$ & $1: 1000$ \\
\hline Bax (D3R2M) Rabbit mAb & Cell Signaling Technology & \#14796 & $1: 100$ & \\
\hline Bcl-2 Rabbit mAb & ABclonal Technology & \#19693 & $1: 100$ & \\
\hline $\begin{array}{l}\text { SignalStain }{ }^{\circledR} \text { Boost IHC Detection Reagent (HRP, } \\
\text { Mouse) }\end{array}$ & Cell Signaling Technology & \#8125 & $1: 200$ & \\
\hline $\begin{array}{l}\text { Biotin-conjugated Affinipure Goat Anti-Rabbit } \\
\lg G(H+L)\end{array}$ & Protein Tech Group Inc., USA & SA00004-2 & $1: 200$ & \\
\hline HRP-conjugated Streptavidin & Protein Tech Group Inc., USA & SA00001-0 & $1: 200$ & \\
\hline $\begin{array}{l}\text { alpha Tubulin Monoclonal Antibody (236- } \\
10,501)\end{array}$ & Thermofisher scientific & A11126 & & $1: 3000$ \\
\hline $\begin{array}{l}\text { HRP-conjugated affinipure goat anti-mouse } \\
\lg G(\mathrm{H}+\mathrm{L})\end{array}$ & Protein Tech Group Inc., USA & SA00001-1 & & $1: 5000$ \\
\hline goat anti-rabbit lgG $(\mathrm{H}+\mathrm{L})$ & Protein Tech Group Inc., USA & SA00001-2 & & 1:5000 \\
\hline
\end{tabular}


at $4{ }^{\circ} \mathrm{C}$ overnight. The avidin-biotinylated horseradish peroxidase complex for a further $30 \mathrm{~min}$. The avidinbiotinylated horseradish peroxidase complex for a further $30 \mathrm{~min}$. Antibody bound to the section was visualized DAB solution, followed by incubation with Bax, Bcl-2, Vimentin, HK2, PKM2, LDHA vimentin after washing the sections with $\mathrm{PBS}$ thrice for $5 \mathrm{~min}$, the slices were then treated with avidin-biotin-peroxidase complexes. The information of antibody used in the experiment are shown in Table 2.

\section{Statistical analysis}

All data distribution analyses were evaluated using GraphPad Prism (Version 8.0, GraphPad Software, La Jolla, USA) while evaluating dependent and independent data with normal distribution. Data are presented as mean \pm standard deviation. The normal distribution was assessed by Kolmogorov Smirnov test. Significant differences among different treatment groups were analyzed using one-way ANOVA tests followed by Tukey's test post hoc. $P<0.05$ was considered statistically significant.

\section{Results}

Effects of SPM supplement on body weight, testis weight and semen quality

Initially, we divided the animals into four groups and their body weight showed no difference. After 8 weeks of treatment, we observed that SPM treatment mice got a higher weight of body and testis compared to saline-treated diabetic mice. With the increase of SPM concentration, the weight was closer to controls (Table 3). Specifically, sperm quality parameters were also examined, in comparison with control group, diabetic mice got lower weight of body and testis. Sperm count is also rarely, with a plenty of abnormal sperm. While a significant increase was observed in the sperm number of both concentrations of SPM treatment mice. And fewer abnormal sperm and the rates of abnormal sperm were observed compared with saline-treated diabetic mice. It worth noting that the protective effect of $5 \mathrm{mg} / \mathrm{kg}$ SPM was closer to that of controls, which is more effective than the concentration of $2.5 \mathrm{mg} / \mathrm{kg}$ SPM.
Effects of SPM supplement on the epididymis, testicular and semen morphology, diameter and area of spermatogenic tubules in diabetic mice

The epididymis and testicular morphology from various groups was shown in Fig. 1. In the salinetreated diabetic mice, a few sperm can be seen in epididymis (Fig. 1A (5)(6)). However, a large number of sperms were observed in the epididymis of control mice (Fig. 1A (1)(2)) and treated with SPM mice (Fig. 1A (9)(10)), among which mice treated with $5 \mathrm{mg} / \mathrm{kg}$ SPM had the highest number of sperm in the epididymis (Fig. 1A (13)(14)). In the salinetreated diabetic mice, the seminiferous tubules were atrophic, with only 1-4 layers of spermatogenic cells in a disordered structure with many vacuoles, the spermatogenic cells were sparsely arranged. In both concentrations of SPM treatments, the seminiferous tubules with regular structure, had multiple layers of densely packed spermatogenic cells. Therefore it preserved the epithelial height (Fig. 1A). The mean area of seminiferous tubules was higher in the control mice $\left(51,357.50 \pm 1564.91 \mu \mathrm{m}^{2}\right)$ than that in the saline-treated diabetic mice $\left(35,871.00 \pm 1105.85 \mu^{2}\right)$, $2.5 \mathrm{mg} / \mathrm{kg}$ SPM treatment $\left(46,545.41 \pm 1274.42 \mu \mathrm{m}^{2}\right)$ and $5 \mathrm{mg} / \mathrm{kg}$ SPM treatment $\left(48,751.93 \pm 1877.53 \mu \mathrm{m}^{2}\right.$; $P<0.05$ for each group), as shown in Fig. 1B. The diameter of the seminiferous tubular of mice in the control mice $(249.85 \pm 2.45 \mu \mathrm{m}), 2.5 \mathrm{mg} / \mathrm{kg}$ SPM treatment $(236.97 \pm 2.27 \mu \mathrm{m})$ and $5 \mathrm{mg} / \mathrm{kg}$ SPM treatment $(240.15 \pm 3.03 \mu \mathrm{m})$ was greater than that in the salinetreated diabetic mice $(219.38 \pm 1.77 \mu \mathrm{m} ; \quad P<0.05)$ (Fig. 1C). Sperm morphology of the control mice was regular in shape. However, the sperm of the DM group exhibited a disorganized morphology, including the headless, abnormal midpiece, tail curled and deformed, while these were rarely occurred in the control mice sperm. After $2.5 \mathrm{mg} / \mathrm{kg}$ SPM treatment, the morphology of part of sperm was improved, but there were still some deformities such as tail curled. While treatment with $5 \mathrm{mg} / \mathrm{kg}$ SPM, most sperm had normal morphology (Fig. 1D).

Table 3 Effects of SPM treatments on the body weight, testis weight and sperm parameters in diabetic mice

\begin{tabular}{|c|c|c|c|c|c|c|}
\hline \multirow[t]{2}{*}{ Group } & \multicolumn{2}{|c|}{ Body weight (g) } & \multirow[t]{2}{*}{ Testis weight (mg) } & \multirow[t]{2}{*}{ Sperm count $\left(\times 10^{7}\right)$} & \multirow{2}{*}{$\begin{array}{l}\text { Abnormal } \\
\text { sperm number } \\
\left(\times 10^{7}\right)\end{array}$} & \multirow{2}{*}{$\begin{array}{l}\text { Abnormal sperm rate } \\
(\%)\end{array}$} \\
\hline & Pre-induction & After treatment & & & & \\
\hline Control & $21.08 \pm 0.38$ & $25.36 \pm 1.54$ & $173.40 \pm 4.65$ & $6.86 \pm 0.57$ & $1.81 \pm 0.32$ & $25.17 \pm 3.91$ \\
\hline DM & $19.52 \pm 0.82^{*}$ & $15.40 \pm 1.62^{* *}$ & $132.40 \pm 20.1^{*}$ & $3.60 \pm 1.63^{* *}$ & $3.00 \pm 1.06^{*}$ & $69.09 \pm 22.07^{* *}$ \\
\hline $\mathrm{DM}+\mathrm{SPM} 2.5 \mathrm{mg} / \mathrm{kg}$ & $19.28 \pm 0.87^{* *}$ & $20.14 \pm 1.06^{\# \#}$ & $171.20 \pm 10.85^{\#}$ & $5.70 \pm 1.36^{\#}$ & $1.50 \pm 0.53^{\#}$ & $32.15 \pm 7.54^{\# \#}$ \\
\hline $\mathrm{DM}+\mathrm{SPM} 5 \mathrm{mg} / \mathrm{kg}$ & $19.38 \pm 0.79^{* *}$ & $22.66 \pm 1.18^{\# \#}$ & $173.53 \pm 7.90^{\#}$ & $6.15 \pm 0.63^{\#}$ & $1.20 \pm 0.41^{\# \#}$ & $25.17 \pm 3.91$ \\
\hline
\end{tabular}

${ }^{*} P<0.05 ;{ }^{*} P<0.01$ vs. Control; ${ }^{\#} P<0.05 ;{ }^{\# \#} P<0.01$ vs. DM 


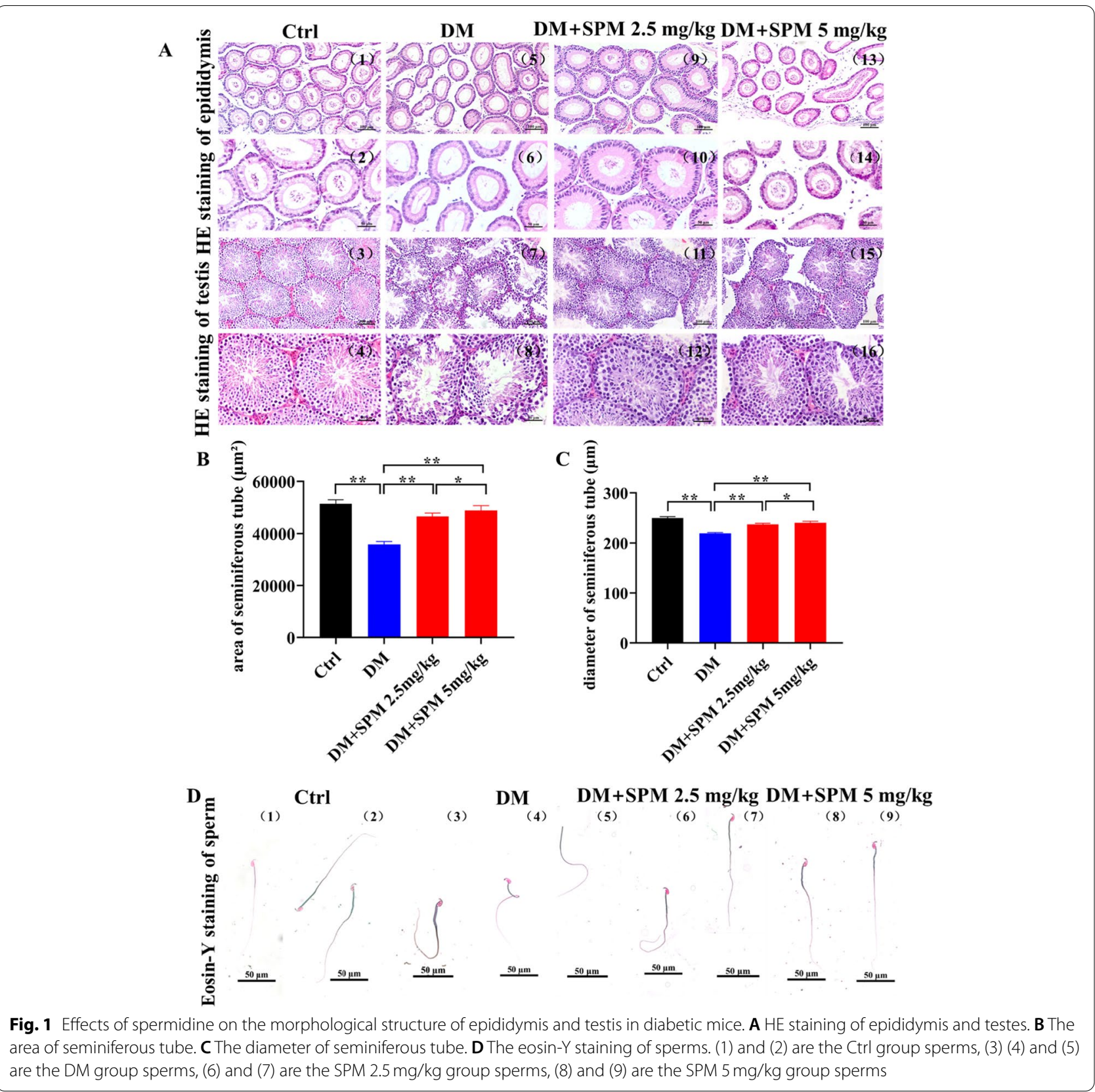

\section{Effects of SPM supplement on apoptosis in testicular tissues from diabetic mice}

We examined the expression of apoptotic factors in testis. The qRT-PCR assay showed that Bcl-2 mRNA expression was downregulated, meanwhile the mRNA expressions of Bax were upregulated in the saline-treated diabetic mice when compared to the control group. And Bcl-2 mRNA expressions were upregulated, with the mRNA expressions of Bax were downregulated in the both concentration of SPM treatment, besides, the ratio of $\mathrm{Bcl}-2 / \mathrm{Bax}$ went down significantly (Fig. 2A). Immunohistochemical results showed the same results (Fig. 2B, C), the red arrows indicate the cells with positive signal. It's worth noting the function of $5 \mathrm{mg} / \mathrm{kg}$ SPM treatment is better than $2.5 \mathrm{mg} / \mathrm{kg}$ SPM treatment, in alleviating the diabetes-induced changes in the apoptosis-related mediators (Fig. 2B, C). The number of $\mathrm{Bcl} 2$-positive cells was counted under light microscope for statistical analysis. Compared with the diabetic mice, the number of the $\mathrm{Bcl} 2$ positive cells in mice treated with 2.5 and $5 \mathrm{mg} / \mathrm{kg} \mathrm{SPM}$ increased significantly $[(87.00 \pm 5.05)$ vs $(120.00 \pm 2.54)$, $(137.00 \pm 2.14), \quad P<0.05]$, the number of the Bax 
positive cells in mice treated with 2.5 and $5 \mathrm{mg} / \mathrm{kg}$ SPM decreased significantly $[(162.00 \pm 2.01)$ vs $(60.00 \pm 2.34)$, (52.00 \pm 3.10$), P<0.05]$ (Fig. 2D).

\section{Effects of SPM supplement on SCs number and cytoskeleton changes, and GATA, WT1 expression in testicular tissues from diabetic mice}

We examined the expression of SCs markers in testis. The mRNA expression of SCs marker gene (GATA, WT1) was downregulated in the testicular tissues of saline-treated DM mice compared to the control group (Fig. 3). Both concentrations of SPM treatments significantly upregulated GATA and WT1 mRNA expression in the testicular tissues compared to saline-treated DM mice (Fig. 3A). Immunohistochemical analysis of Vimentin protein expression in the testicular tissues from the different treatment groups and diabetic mice with saline, which showed a decrease in the number of SCs in the testicular tissues compared to the control group, while the cytoskeleton structure of SCs in SPM 5 group is more in order than SPM 2.5 group (Fig. 3B), The red arrows indicate the cells with positive signal. And compered with diabetic mice, the number of the Vimentin positive cells in mice treated with 2.5 and $5 \mathrm{mg} / \mathrm{kg} \mathrm{SPM}$ increased significantly $[(191.00 \pm 1.91)$ vs $(292.00 \pm 2.54)$, (321.00 \pm 1.85$), P<0.05]$ (Figs. $3 \mathrm{C}$ and 4 ).

\section{Effects of SPM supplement on the expression of glycolytic rate-limiting enzyme gene in testicular tissues from diabetic mice}

We examined the expression of glycolytic rate-limiting enzyme gene in the testis. In the qRT-PCR assay, the mRNA expression of HK2, PKM2 and LDHA were significantly decreased in diabetic mice with saline, which was almost improved in the SPM $2.5 \mathrm{mg} / \mathrm{kg}$ group and SPM $5 \mathrm{mg} / \mathrm{kg}$ group $(P<0.05$; Fig. $4 \mathrm{~A})$, which protein levels in the same trend by Western blot (Fig. 4B). Immunohistochemical analysis confirmed that the expression of glycolytic rate-limiting enzyme gene (HK2, PKM2, LDHA)-positive cells in STZ-treated groups was significantly decreased compared with the control groups $(P<0.05$; Fig. 5A, B, C, D), The red arrows indicate the cells with positive signal. Consistently, SPM treatments in both concentrations increased the number of HK2, PKM2 and LDHA-positive cells in the testicular tissues of diabetic mice when compared to treatment with saline $(P<0.05$; Fig. 5A, B, C, D).

\section{Discussion}

It was reported that the proportion of infertility couples accounts for about $1 / 10$ of the total population worldwide, and half the causes lie in male [19]. The onset of diabetes mellitus (DM) is becoming younger and younger, which leads to sexual dysfunction, abnormal testicular structure and spermatogenic dysfunction, which is one of the important reasons for male infertility [20]. Overall, hyperglycemia is an important marker of type 1 diabetes mellitus (T1DM), numerous studies have shown that hyperglycemia give rise to a decrease in male fertility by damaging the reproductive endocrine of the hypothalamic-pituitary-gonadal axis [21], which could induce abnormal spermatogenesis. Moreover, hyperglycemia in testis aggravated the morphological and functional changes of testis and epididymis, impaired semen quality as well as dwindled sperm count, sperm motility and semen volume $[1,22]$. In the previous studies, using a single intraperitoneal injection of $120 \mathrm{mg} / \mathrm{kg} \mathrm{STZ} \mathrm{[23],}$ the STZ-induced diabetic mice was constructed successfully, along with an increase in blood sugar, the body weight and testicles weight of DM mice was significantly reduced [24]. Meanwhile, serious histological damage, including reduced cross-sectional area of spermatogenic tubules and reduced diameter and morphological destruction was caused [25]. What's more, reduced spermatogenic cells and sperm count, and increased rate of malformed sperms are detected in DM mice [26]. In this study, our results were consistent with all of the above literatures, which makes meaningful by exploring the spermatogenic dysfunction in diabetic males forward.

Spermidine (SPM) is a sufficient natural polyamine, which contained in all organisms from bacteria to human and presented in diets, such as nuts, beans and so on. Studies have shown that SPM has a variety of pharmacological functions such as anti-inflammatory, anti-oxidation, promoting autophagy and inhibiting lipid formation [9, 10, 27]. Excitingly, SPM has a protective effect on the DM, exogenous SPM supplementation could alleviate myocardial fibrosis in diabetic cardiomyopathy [12]. Besides, SPM also could attenuate hemoglobin glycation and lipid peroxidation in diabetes rats $[13,28]$. Meanwhile, It has been found that SPM plays pleiotropic functions, such as it guarantees sperm to perform its acrosomal reaction at the right time [29], improves sperm motility [30], increases the rate of normal sperm morphology and enhances

(See figure on next page.)

Fig. 2 Effects of spermidine on apoptosis of spermatogenic cells in diabetic mics. The red arrows indicate the cells with positive signal. A (1) The expression of $\mathrm{BCl}-2$ in testis detected by qRT-PCR. (2) The expression of Bax in testis detected by qRT-PCR. (3) The expression of Bcl-2/Bax in testis detected by qRT-PCR. B The expression of $\mathrm{BCl}-2$ in spermatogenic tubules was detected by immunohistochemistry. $\mathbf{C}$ The expression of Bax in spermatogenic tubules was detected by immunohistochemistry. D:(1) BCl-2 positive cell count in the testis. (2) Bax positive cell count in the testis 
A

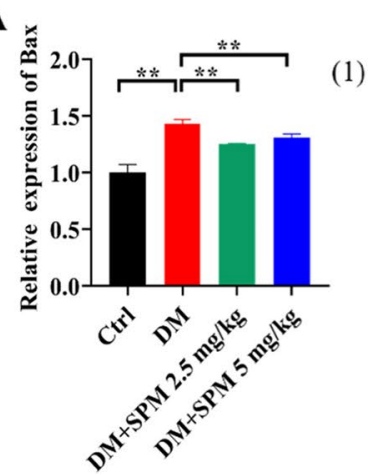

B

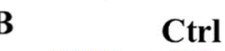

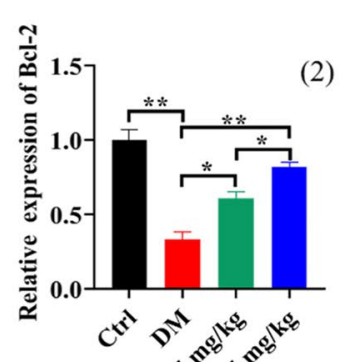

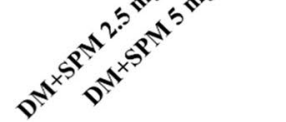

DM DM+SPM $2.5 \mathrm{mg} / \mathrm{kg} \mathrm{DM+SPM} 5 \mathrm{mg} / \mathrm{kg}$
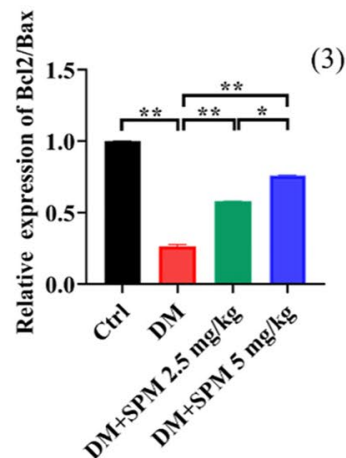

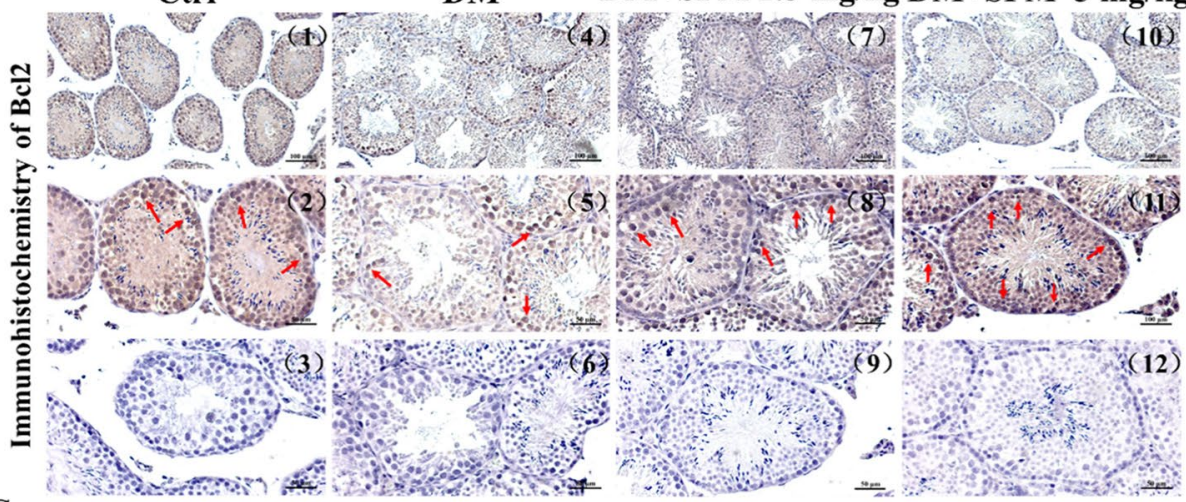

C

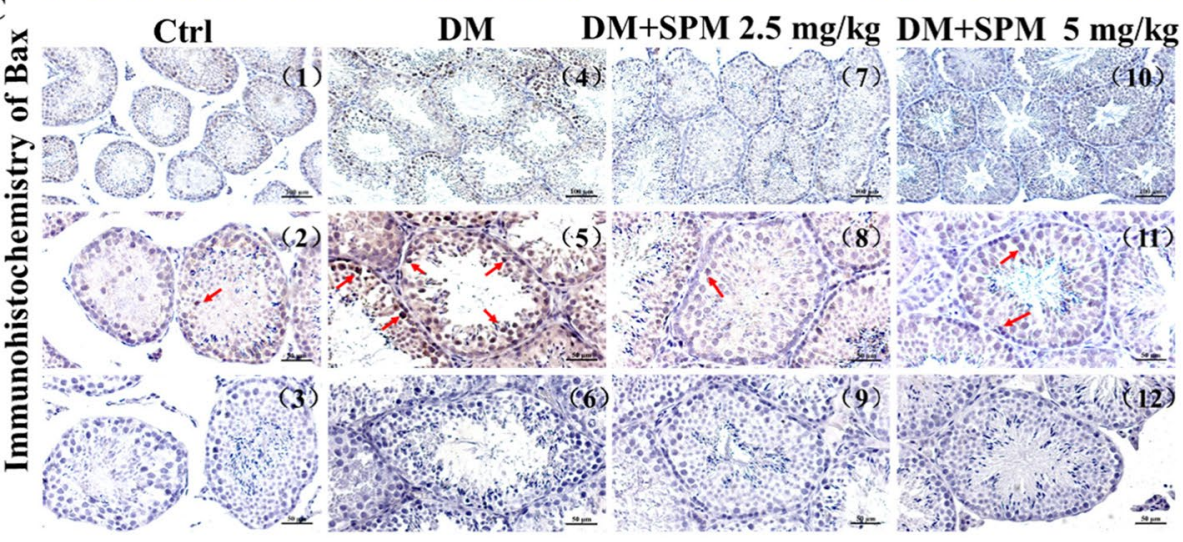

D

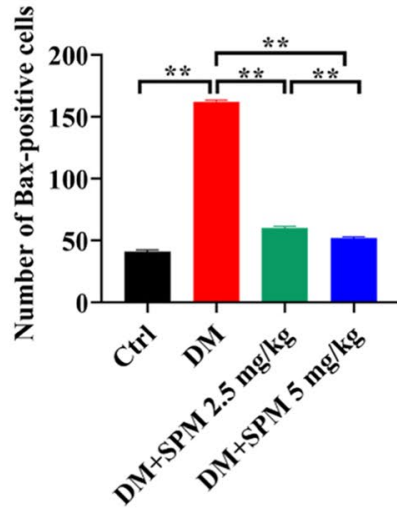

(1)

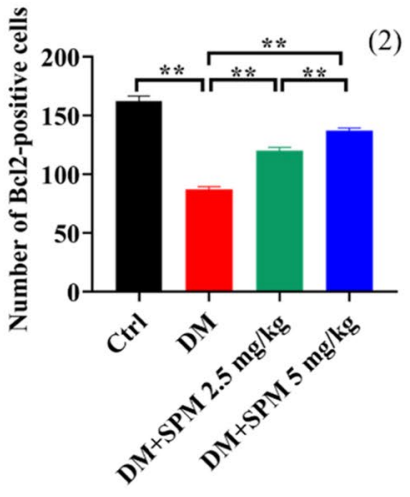

Fig. 2 (See legend on previous page.) 


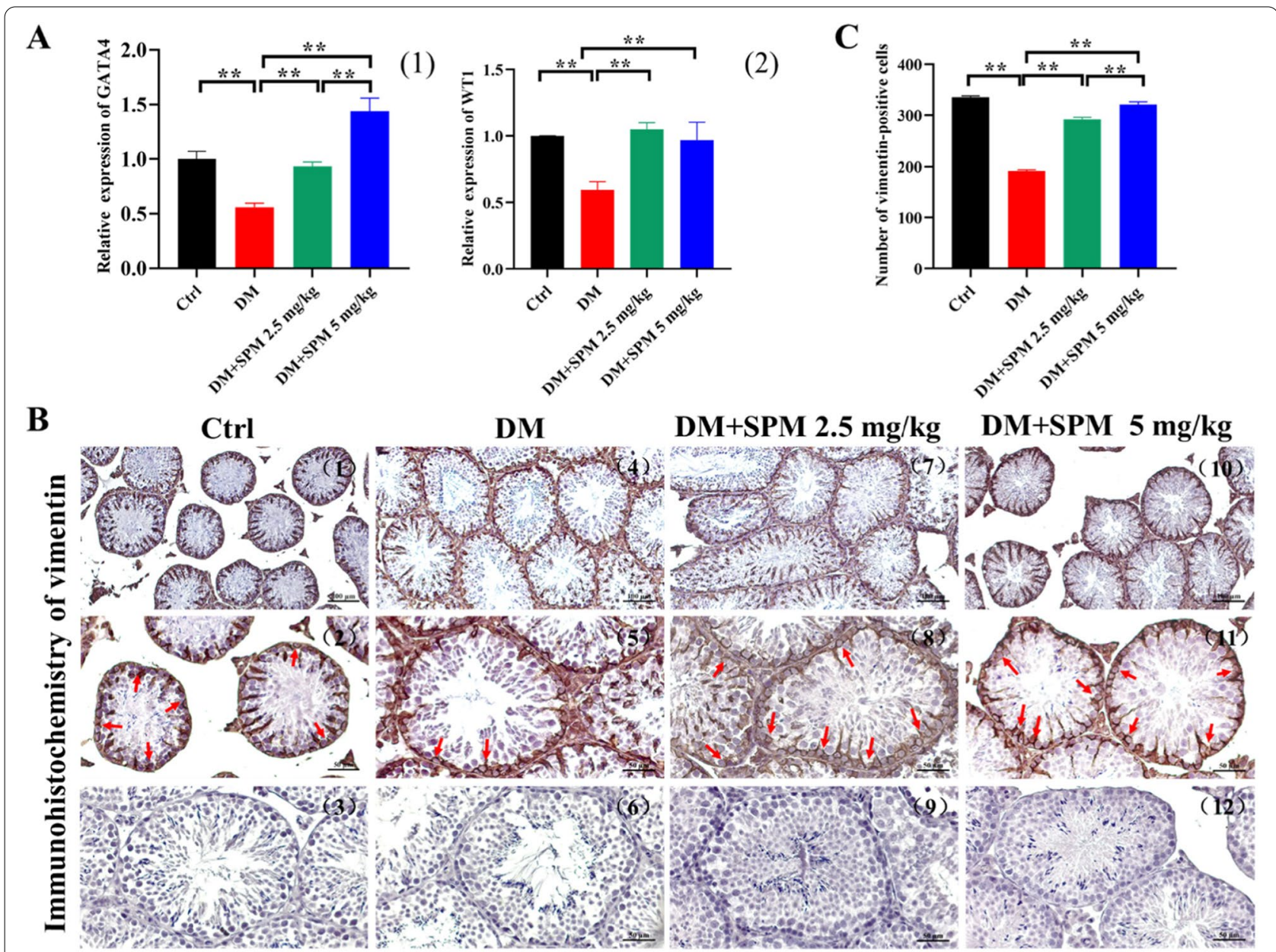

Fig. 3 Effects of spermidine on the number and function of testicular Sertoli cells in diabetic mice. The red arrows indicate the cells with positive signal. A (1) The expression of GATA4 in testis detected by qRT-PCR. (2) The expression of WT1 in testis detected by qRT-PCR. B The expression of Vimentin in spermatogenic tubules was detected by immunohistochemistry. C The expression of Vimentin in spermatogenic tubules was detected by immunohistochemistry

superoxide dismutase activity [31]. Recent studies have shown that intaking exogenous spermine could rescue triptolide-induced testicular dysfunction, by increasing the expression of genes related to spermatogenic events and increasing the reduced number of offspring [32]. Addition of L-arginine and polyamines to human sperm cells from diabetic asthenozoospermic patients played a beneficial role on sperm motility [33]. In the present study, the decreased in the number of abnormal sperm, significantly increased in the weight of testis and epididymis as well as sperm count were detected in DM mice after SPM supplementation, which indicated a good improvement of SPM on the spermatogenesis dysfunction in DM mice. Furthermore, more and more literatures have proved that in the testes with hyperglycemia, the expression profiles of apoptosis related proteins $\mathrm{Bax}$ and the $\mathrm{Bax} / \mathrm{Bcl}-2$ ratio were upregulated, as well Bcl-2 was downregulated, which was accompanied with the increasing number of apoptotic spermatogenic cells [34, 35]. While SPM have been clarified that it could abrogate the apoptosis of spermatogenic cells by reducing apoptosis independent of autophagy, upregulating Bcl-2 and decreasing Bax expression [36, 37]. Our findings revealed that in DM mice, SPM played an important role in preventing apoptosis through upregulating $\mathrm{Bcl}-2$ and down-regulating $\mathrm{Bax}$ in the testes. Furthermore, this study explained that SPM could significantly reduce spermatogonia dysfunction in male diabetes by against apoptosis mediated in spermatogenic cells, while it has not been reported in previous literature.

Interestingly, SCs are the only somatic cells in the seminiferous tubules that can secrete a variety of growth factors and play a key role in spermatogenesis [38]. Nevertheless, SCs are often the target cells of external toxic substances, which have toxic actions on male 


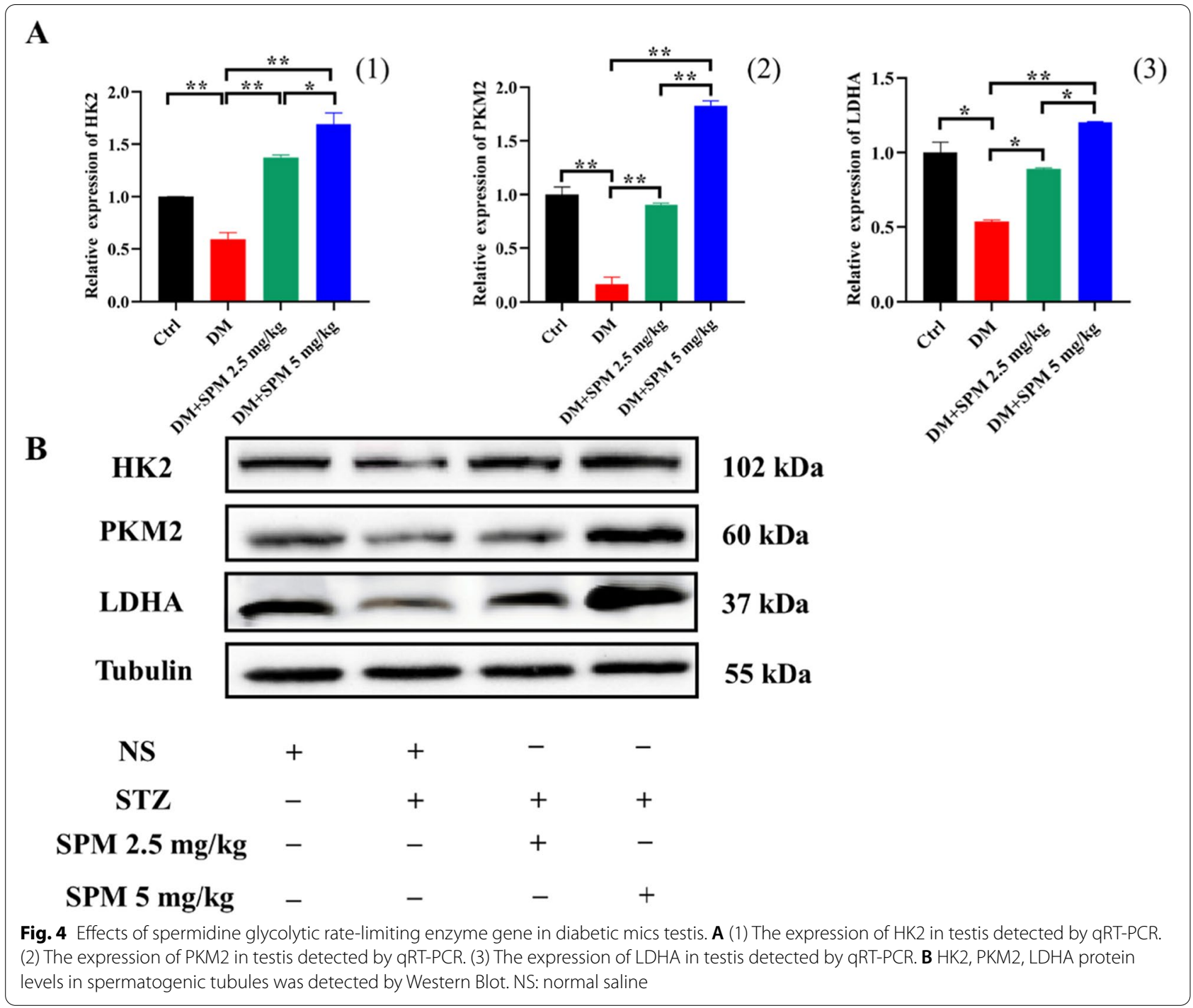

reproductive function by damaging the structure and function of SCs [39]. Patients with DM are often accompanied by low levels of androgen and reduction of inhibin B and AR expression, which suggested SCs function is destroyed [40]. High glucose level in DM prevented the maturation of SCs in cultured testicular tissue, resulting in a decreased number of SCs and a significant decrease in the area of spermatogenic tubules [41]. Vimentin, WT1 and GATA are marker genes of SCs, which are stably expressed in the nucleus of testicular SCs. Especially, the expression of Vimentin is associated with epithelial structural integrity [42], which forms the skeletal structure of the SCs [43]. In the testis of STZ-induced diabetic mice, the expression of Vimentin was down-regulated, the cytoskeleton structure of SCs was destroyed, and the cell function decreased as well [44]. Results in the present study was consistent with previous studies in our
DM mice, but the expression of Vimentin was upregulated after SPM supplement, which suggesting that SPM plays a vital role in maintaining the regular cytoskeleton of seminiferous tubule in diabetic mice. In advance of this study, the expressions levels of WTI and GATA in testis were decreased in diabetic mice, which manifesting the decline in the number and function of SCs [22, 45]. In our study, we also verified a significant decrease in the expression levels of WT1 and GATA in diabetic testis, which was eliminated by SPM supplement in DM mice. Summarily, DM impairs the cytoskeleton structure and function of SCs, SPM can be used to improve diabetes by reversing the morphology, structure and function of SCs.

In general, testis has been reported to be a naturally oxygen-deprived organ, energy produced by glycolysis of SCs is an important metabolic control point for spermatogenesis, as well SCs could quickly provide adenosine 


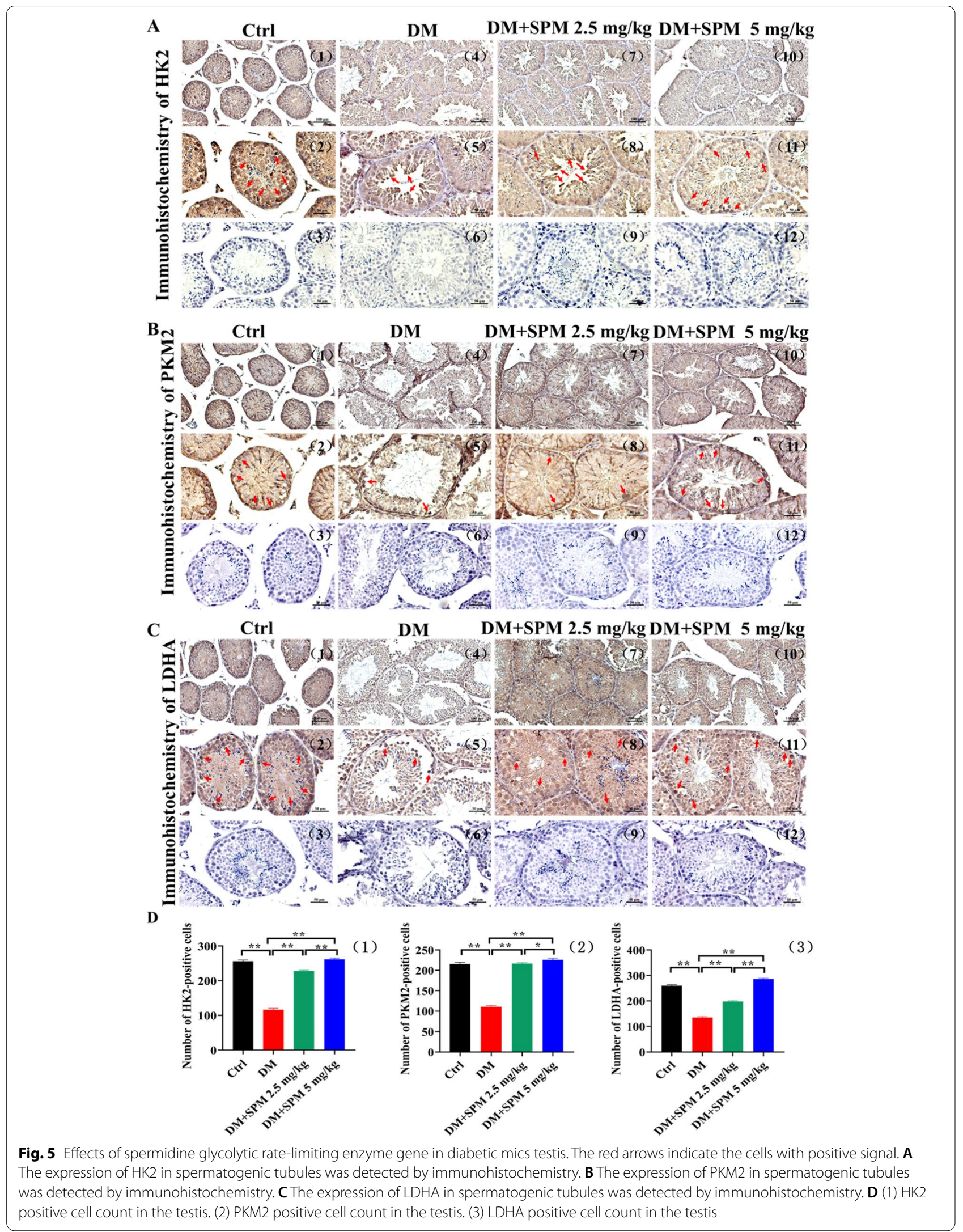


triphosphate and lactate to meet the needs of rapidly proliferating spermatogenic cells for energy and substances $[46,47]$. The regulatory mechanism during the process of transporting glucose to SCs, LDHA catalyzing pyruvate into lactate, as well the transporting lactate to spermatogenic cells plays an important role in spermatogenesis $[47,48]$. Previous studies have demonstrated that the LDHA is reduced in testes from T1DM patients [49], similarly, the expression of key glycolytic enzymes HK2, PKM2 and LDHA in the testis of diabetic mice are significantly reduced, which leads to glycogen accumulation, cut down of lactate production of SCs, eventually disorders the energy metabolism of spermatogenic cells and induces a significant cell apoptosis [50, 51]. Pioglitazone as a hypoglycemic drug that functions by enhancing insulin sensitivity in the target tissue, which can stimulate the glucose consumption in human SCs to more than double, and increase the glycolysis rate and lactate production, thus, the better medicine for maintaining and improving the spermatogenic events caused by DM [52]. Similarly, lipoic acid has been reported to enhance the absorption of glucose into cells and improve islet function and glucose metabolism, its supplementation could inhibit the apoptosis of SCs and increase the ability of ATP production, which improved sperm motility and concentration in DM rats. When SCs are exposed to pharmacological doses of L-theanine $(50 \mu \mathrm{M})$, it could promote cell proliferation and glycolysis rate, maintain energy requirement for cell component synthesis, and support to build new cells [53]. Meanwhile, SPM metabolism is sensitive to glycolysis impairment in tumor cells [54], mechanistically, when SPM biosynthesis is impaired, the reduced aerobic glycolysis could inhibit cell proliferation and promote inflammation [55]. Our experimental results have proved that DM could down-regulated the expressions of HK2, PKM2 and LDHA in the testis of DM mice, while SPM supplementation increased the mRNA and protein expressions of HK2, PKM2 and LDHA in the testis of DM mice. By the same time, when DM patients take a combination of insulin and melatonin for the therapy, which could better maintain the protein levels of glycolysis-related enzymes at normal levels and improve the dyszoospermia [56]. However, the findings of this study are still in the preliminary phases, the latent molecular mechanisms, such as what factors mediate the change of glycolysis rate-limiting enzyme gene in diabetes mice with the SPM supplement, are still vague and require further investigation.

In conclusion, our results manifested that the protective effects of SPM on the DM-induced male reproductive damage in mice by improving the pathological structure of testis, inhibiting apoptosis of spermatogenic

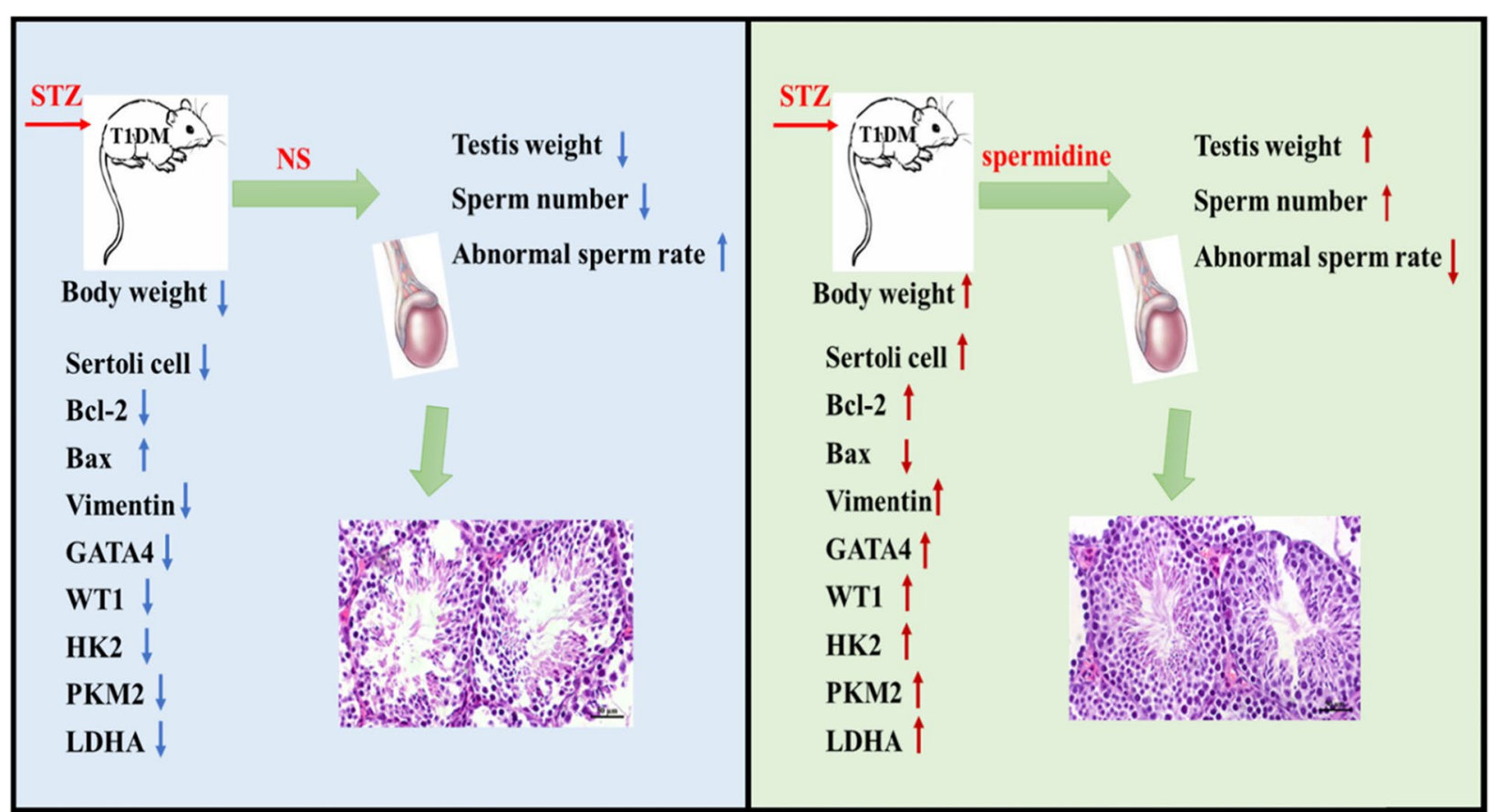

Fig. 6 In vivo supplementation of the spermidine (SPM) effectively protective DM-induced male reproductive damage by improving the pathological structure of testis, inhibiting apoptosis of spermatogenic cells and promoting proliferation. Eventually, SPM could ameliorate the structure and function of SCs in DM mice, increase the expression of glycolytic rate-limiting enzyme 
cells and promoting proliferation. Eventually, mechanistic results showed that SPM ameliorated the structure and function of SCs in DM mice, increased the expression of glycolytic rate-limiting enzyme, and that the upregulated HK2, PKM2, LDHA expression may have a positive effect on the dyszoospermia in DM mice (Fig. 6).

\section{Abbreviations}

SPM: Spermidine; DM: Diabetes mellitus; T1DM: Type 1 diabetes mellitus; STZ: Streptozotocin; SCs: Sertoli cells; WT1: Wilmstumor1; HK2: Hexokinase 2; PKM2: Pyruvate kinase M2; LDHA: Lactate dehydrogenase A.

\section{Acknowledgements}

None.

\section{Authors' contributions}

JYW, ZHT and XCL designed the whole study. JYW, DM, ML, YPT, GT, YTL and $\mathrm{OZ}$ performed the experiments and analyzed the data. MXL and XC performed the statistical analysis. JYW and XCL wrote the manuscript. All authors approved the manuscript for submission.

\section{Funding}

The present study was supported by the China National Natural Science Fund (Nos. 81860733), The Science and Technology Fund of Guizhou Province (No. Qian Basic [2019]1344), Hunan Natural Science Foundation Youth Project (No. 2020JJ5500), Outstanding youth fund of The Education Department of Hunan Province (NO. 18B584), The Natural Science Foundation of Guangxi in China (No. 2021 GXNSFBA220010), Hunan Province Innovation and Entrepreneurship Training Program for College Students (No. S202010555129 and X202010555390).

\section{Availability of data and materials}

Not applicable.

\section{Declarations}

\section{Ethics approval and consent to participate}

all members of this team in this research work will follow the principle of humanitarian, ensure laboratory animal welfare ethics, and strictly abide by the laboratory animal center at the university of south China related rules and regulations, accept the experimental animal welfare ethical review committee of the guidance and supervision and inspection.

\section{Consent for publication}

Not applicable.

\section{Competing interests}

The authors declare that the research was conducted in the absence of any commercial or financial relationships that could be construed as a potential conflict of interest.

\section{Author details}

${ }^{1}$ Clinical Anatomy \& Reproductive Medicine Application Institute, Heng Yang Medical College, University of South China, Hengyang 421001, Hunan, China. ${ }^{2}$ Postdoctoral Station for Basic Medicine, Hengyang Medical College, University of South China, Hengyang 421001, Hunan, China. ${ }^{3}$ China Reproductive Medicine Center, The Affiliated Hospital of Youjiang Medical University for Nationalities, Baise 533000, Guangxi, China.

Received: 13 August 2021 Accepted: 12 January 2022

Published online: 07 March 2022

\section{References}

1. Maresch CC, Stute DC, Alves MG, Oliveira PF, de Kretser DM, Linn T. Diabetes-induced hyperglycemia impairs male reproductive function: a systematic review. Hum Reprod Update. 2018;24:86-105.
2. Xu Y, Wang L, He J, Bi Y, Li M, Wang T, et al. Prevalence and control of diabetes in Chinese adults. JAMA. 2013;310:948-59.

3. Akbarian F, Rahmani M, Tavalaee M, Abedpoor N, Taki M, Ghaedi K, et al. Effect of different high-fat and advanced glycation end-products diets in obesity and diabetes-prone C57BL/6 mice on sperm function. Int J Fertil Steril. 2021;15:226-33.

4. Ettinger S. Diabetic nephropathy, chronic kidney disease. In: Nutritional pathophysiology of obesity \& its comorbidities; 2017. p. 161-89.

5. Thomas GN, Jiang CQ, Taheri S, Xiao ZH, Tomlinson B, Cheung BM, et al. A systematic review of lifestyle modification and glucose intolerance in the prevention of type 2 diabetes. Curr Diabetes Rev. 2010;6:378-87.

6. Baccetti B, La Marca A, Piomboni P, Capitani S, Bruni E, Petraglia F, et al. Insulin-dependent diabetes in men is associated with hypothalamo-pituitary derangement and with impairment in semen quality. Hum Reprod. 2002;17:2673-7.

7. Carvalho MG, Silva KM, Aristizabal VHV, Ortiz PEO, Paranzini CS, Melchert A, et al. Effects of obesity and diabetes on sperm cell proteomics in rats. J Proteome Res. 2021;20:2628-42.

8. Condorelli RA, La Vignera S, Mongioi LM, Alamo A, Calogero AE. Diabetes mellitus and infertility: different pathophysiological effects in type 1 and type 2 on sperm function. Front Endocrinol (Lausanne). 2018;9:268.

9. Madeo F, Eisenberg T, Pietrocola F, Kroemer G. Spermidine in health and disease. Science. 2018;359(6374).

10. Madeo F, Eisenberg T, Büttner S, Ruckenstuhl C, Kroemer G. Spermidine: a novel autophagy inducer and longevity elixir. Autophagy. 2010;6:160-2.

11. Shahin NN, El-Nabarawy NA, Gouda AS, Megarbane B. The protective role of spermine against male reproductive aberrations induced by exposure to electromagnetic field - an experimental investigation in the rat. Toxicol Appl Pharmacol. 2019;370:117-30.

12. Hu J, Lu X, Zhang X, Shao X, Wang Y, Chen J, et al. Exogenous spermine attenuates myocardial fibrosis in diabetic cardiomyopathy by inhibiting endoplasmic reticulum stress and the canonical Wnt signaling pathway. Cell Biol Int. 2020;44:1660-70.

13. Mendez JD, Balderas FL. Inhibition by L-arginine and spermidine of hemoglobin glycation and lipid peroxidation in rats with induced diabetes. Biomed Pharmacother. 2006;60:26-31.

14. Sadasivan SK, Vasamsetti B, Singh J, Marikunte VV, Oommen AM, Jagannath $M R$, et al. Exogenous administration of spermine improves glucose utilization and decreases bodyweight in mice. Eur J Pharmacol. 2014;729:94-9.

15. Ma J, Meng X, Liu Y, Yin C, Zhang T, Wang P, et al. Effects of a rhizome aqueous extract of Dioscorea batatas and its bioactive compound, allantoin in high fat diet and streptozotocin-induced diabetic mice and the regulation of liver, pancreas and skeletal muscle dysfunction. J Ethnopharmacol. 2020;259:112926.

16. Demirci T, Sahin E. The effect of chronic stress and obesity on sperm quality and testis histology in male rats; a morphometric and immunohistochemical study. Histol Histopathol. 2019;34:287-302.

17. Lei $X$, Huo $P$, Wang $Y$, Xie Y, Shi Q, Tu H, et al. Lycium barbarum polysaccharides improve testicular spermatogenic function in Streptozotocininduced diabetic rats. Front Endocrinol (Lausanne). 2020:11:164.

18. Le J, Lei X, Ren Y, Li Z, Tu H, Ding F, et al. Exogenous oestradiol benzoate induces male mice azoospermia through modulation of oxidative stress and testicular metabolic cooperation. Mol Med Rep. 2019;19:4955-63.

19. Agarwal A, Baskaran S, Parekh N, Cho C-L, Henkel R, Vij S, et al. Male infertility. Lancet. 2021;397:319-33.

20. Singh R, Singh K. Male infertility: understanding, causes and treatment; 2017.

21. Costanzo PR, Suarez SM, Scaglia HE, Zylbersztein C, Litwak LE, Knoblovits $P$. Evaluation of the hypothalamic-pituitary-gonadal axis in eugonadal men with type 2 diabetes mellitus. Andrology. 2014;2:117-24.

22. La Vignera S, Condorelli R, Vicari E, D'Agata R, Calogero AE. Diabetes mellitus and sperm parameters. J Androl. 2012;33:145-53.

23. Liu C, Zhang C, Du H, Geng X, Zhao H. Remote ischemic preconditioning protects against ischemic stroke in streptozotocin-induced diabetic mice via anti-inflammatory response and anti-apoptosis. Brain Res. 2019;1724:146429.

24. Xu X, Liang T, Wen Q, Lin X, Tang J, Zuo Q, et al. Protective effects of total extracts of Averrhoa carambola L. (Oxalidaceae) roots on streptozotocininduced diabetic mice. Cell Physiol Biochem. 2014;33:1272-82. 
25. Dadras S, Abdollahifar MA, Nazarian H, Ghoreishi SK, Fallahnezhad S, Naserzadeh P, et al. Photobiomodulation improved stereological parameters and sperm analysis factors in streptozotocin-induced type 1 diabetes mellitus. J Photochem Photobiol B. 2018;186:81-7.

26. Mangoli E, Talebi AR, Anvari M, Pourentezari M. Effects of experimentallyinduced diabetes on sperm parameters and chromatin quality in mice. Iran J Reprod Med. 2013;11:53-60.

27. Pegg AE. The function of spermine. IUBMB Life. 2014;66:8-18.

28. Gugliucci A, Menini T. The polyamines spermine and spermidine protect proteins from structural and functional damage by AGE precursors: a new role for old molecules? Life Sci. 2003;72:2603-16.

29. Rubinstein S, Breitbart H. Role of spermine in mammalian sperm capacitation and acrosome reaction. Biochem J. 1991;278(Pt 1):25-8.

30. Singh BP, Saha I, Nandi I, Swamy MJ. Spermine and spermidine act as chemical chaperones and enhance chaperone-like and membranolytic activities of major bovine seminal plasma protein, PDC-109. Biochem Biophys Res Commun. 2017;493:1418-24.

31. Lefevre PL, Palin MF, Murphy BD. Polyamines on the reproductive landscape. Endocr Rev. 2011;32:694-712.

32. Zhao Q, Huang JF, Cheng Y, Dai MY, Zhu WF, Yang XW, et al. Polyamine metabolism links gut microbiota and testicular dysfunction. Microbiome. 2021;9:224.

33. Morales ME, Rico G, Bravo C, Tapia R, Alvarez C, Mendez JD. Progressive motility increase caused by L-arginine and polyamines in sperm from patients with idiopathic and diabetic asthenozoospermia. Ginecol Obstet Mex. 2003;71:297-303.

34. Liu Y, Yang Z, Kong D, Zhang Y, Yu W, Zha W. Metformin ameliorates testicular damage in male mice with Streptozotocin-induced type 1 diabetes through the PK2/PKR pathway. Oxidative Med Cell Longev. 2019;2019:5681701.

35. Koh PO. Streptozotocin-induced diabetes increases apoptosis through JNK phosphorylation and Bax activation in rat testes. J Vet Med Sci. 2007:69:969-71

36. Yao D, GangYi Y, QiNan W. Autophagic dysfunction of $\beta$ cell dysfunction in type 2 diabetes, a double-edged sword. Genes Dis. 2021;8:438-47.

37. Fan J, Yang X, Li J, Shu Z, Dai J, Liu X, et al. Spermidine coupled with exercise rescues skeletal muscle atrophy from D-gal-induced aging rats through enhanced autophagy and reduced apoptosis via AMPK-FOXO3a signal pathway. Oncotarget. 2017;8:17475-90.

38. Ravel C, Jaillard S. The Sertoli cell. Morphologie. 2011;95:151-8.

39. Zhu Q, Li X, Ge RS. Toxicological effects of cadmium on mammalian testis. Front Genet. 2020;11:527.

40. Arikawe AP, Oyerinde A, Olatunji B II, Obika LF. Streptozotocin diabetes and insulin resistance impairment of spermatogenesis in adult rat testis: central vs. local mechanism. Niger J Physiol Sci. 2012;27:171-9.

41. Tavares RS, Portela JMD, Sousa MI, Mota PC, Ramalho-Santos J, Amaral S. High glucose levels affect spermatogenesis: an in vitro approach. Reprod Fertil Dev. 2017;29:1369-78

42. Kopecky M, Semecky V, Nachtigal P. Vimentin expression during altered spermatogenesis in rats. Acta Histochem. 2005;107:279-89.

43. He D, Zhang D, Wei G, Lin T, Li X. Cytoskeleton vimentin disruption of mouse sertoli cells injured by nitrogen mustard in vitro. J Androl. 2007;28:389-96.

44. Xu Y, Lei H, Guan R, Gao Z, Li H, Wang L, et al. Prophylactic protective effects and its potential mechanisms of Icarisidell on streptozotocin induced spermatogenic dysfunction. Int J Mol Sci. 2014;15:16100-13.

45. Liang J, Wang N, He J, Du J, Guo Y, Li L, et al. Induction of Sertoli-like cells from human fibroblasts by NR5A1 and GATA4. eLife. 2019;8:e48767.

46. Yi XD, Zhanf YN, Xiao S, Lei XC. Role and regulatory mechanism of glycometabolism of Sertoli cells in spermatogenesis. Zhonghua Nan Ke Xue. 2019;25:923-7.

47. Boussouar F, Benahmed M. Lactate and energy metabolism in male germ cells. Trends Endocrinol Metab. 2004;15:345-50.

48. Alves MG, Martins AD, Jarak I, Barros A, Silva J, Sousa M, et al. Testicular lactate content is compromised in men with Klinefelter syndrome. Mol Reprod Dev. 2016;83:208-16.

49. Alves MG, Martins AD, Moreira PI, Carvalho RA, Sousa M, Barros A, et al. Metabolic fingerprints in testicular biopsies from type 1 diabetic patients. Cell Tissue Res. 2015;362:431-40.
50. Alves MG, Martins AD, Cavaco JE, Socorro S, Oliveira PF. Diabetes, insulinmediated glucose metabolism and Sertoli/blood-testis barrier function. Tissue Barriers. 2013;1:e23992.

51. Alves MG. Energetics of the male reproduction. Encyclopedia Reprod. 2018;1:451-7.

52. Meneses MJ, Bernardino RL, Sa R, Silva J, Barros A, Sousa M, et al. Pioglitazone increases the glycolytic efficiency of human Sertoli cells with possible implications for spermatogenesis. Int J Biochem Cell Biol. 2016:79:52-60

53. Dias TR, Bernardino RL, Alves MG, Silva J, Barros A, Sousa M, et al. L-Theanine promotes cultured human Sertoli cells proliferation and modulates glucose metabolism. Eur J Nutr. 2019;58:2961-70.

54. Ruiz-Perez MV, Medina MA, Urdiales JL, Keinanen TA, Sanchez-Jimenez F. Polyamine metabolism is sensitive to glycolysis inhibition in human neuroblastoma cells. J Biol Chem. 2015;290:6106-19.

55. Monticelli LA, Buck MD, Flamar AL, Saenz SA, Tait Wojno ED, Yudanin NA, et al. Arginase 1 is an innate lymphoid-cell-intrinsic metabolic checkpoint controlling type 2 inflammation. Nat Immunol. 2016;17:656-65.

56. Rocha CS, Martins AD, Rato L, Silva BM, Oliveira PF, Alves MG. Melatonin alters the glycolytic profile of Sertoli cells: implications for male fertility. Mol Hum Reprod. 2014;20:1067-76.

\section{Publisher's Note}

Springer Nature remains neutral with regard to jurisdictional claims in published maps and institutional affiliations.
Ready to submit your research? Choose BMC and benefit from:

- fast, convenient online submission

- thorough peer review by experienced researchers in your field

- rapid publication on acceptance

- support for research data, including large and complex data types

- gold Open Access which fosters wider collaboration and increased citations

- maximum visibility for your research: over 100M website views per year

At BMC, research is always in progress.

Learn more biomedcentral.com/submissions 